\title{
Cell culture and passaging alters gene expression pattern and proliferation rate in rheumatoid arthritis synovial fibroblasts
}

\author{
Elena Neumann*1, Birgit Riepl2, Anette Knedla1', Stephanie Lefèvre', Ingo H Tarner1', Joachim Grifka³, \\ Jurgen Steinmeyer ${ }^{4}$, Jurgen Schölmerich², Steffen Gay ${ }^{5}$ and UIf Müller-Ladner ${ }^{1}$
}

\begin{abstract}
Introduction: Rheumatoid arthritis synovial fibroblasts (RASF) are key players in synovial pathophysiology and are therefore examined extensively in various experimental approaches. We evaluated, whether passaging during culture and freezing has effects on gene expression and cell proliferation.

Methods: RASF were passaged for up to 8 passages. RNA was isolated after each passage and cDNA arrays were performed to evaluate the RNA expression pattern during passaging. In addition, doubling time of the cells was also measured.

Results: From passages 2-4, mRNA expression did not change significantly. Gene expression in RASF started to change in passages 5-6 with 7-10\% differentially expressed genes. After passages 7-8, more than $10 \%$ of the genes were differentially expressed. The doubling rate was constant for up to 5 passages and decreased after passages 6-8. After freezing, gene expression of the second passage is comparable to gene expression prior to freezing.

Conclusions: The results of this study show, that experiments, which examine gene expression of RASF and shall reflect or imitate an in vivo situation, should be limited to early culture passages to avoid cell culture effects. It is not necessary to stop culturing SF after a few passages, but to keep the problems of cell culture in mind to avoid false positive results. Especially, when large-scale screening methods on mRNA level are used. Of note, freezing does not affect gene expression substantially.
\end{abstract}

\section{Introduction}

Predominant features of rheumatoid arthritis (RA) are synovial hyperplasia, synovial cell activation and articular inflammation associated with subsequent cartilage and bone destruction [1]. In this scenario, activated synovial fibroblasts (SF) are key players in joint destruction at the site of invasion into articular cartilage and bone [1-5]. They maintain their aggressive phenotype towards cartilage even when primarily cultured and thereafter coimplanted together with normal human cartilage into immunodeficient severe combined immunodeficient mice (SCID) mice for an extended period of time [5].

\footnotetext{
* Correspondence: e.neumann@kerckhoff-klinik.de

1 Department of Internal Medicine and Rheumatology, University of Gießben, Kerckhoff-Klinik, D-61231 Bad Nauheim, Benekestr. 2-8, Germany Full list of author information is available at the end of the article
}

To inhibit the progressive growth at the invasion zone followed by cartilage and bone degradation without interfering with physiologic matrix remodeling, identification of pathways operative specifically in RASF and not in SF of other origin (e.g. osteoarthritis SF) is essential. Therefore, genes showing a dysregulation that is restricted to RASF are the experimental target of numerous research groups [6-17].

Various strategies, for example differential display, subtractive cell-hybridization, and cDNA arrays and many more, have been developed to examine tissue- and disease-specific differences in gene expression [10,11,18-23]. In addition, a variety of experiments that address the evaluation of pathways of cartilage and bone destruction and their underlying mechanisms were performed with in vitro cultured RASF populations isolated from tissue samples obtained during synovial joint replacement. 
Moreover, to test the effects of new drugs or novel treatment strategies, in vitro or in animal models experiments with cultured RASF are essential [8,10,14,24-26].

In contrast to these goals and these experimental approaches, even when the RASF appear activated and 'transformed', they are not fast growing or immortal tumor cell lines, which show a constant geno- and/or phenotype for an extended cultivation period. They are slow to moderately proliferating cell populations, which during cultivation may alter their in vivo phenotype when devoid of their normal environment. In addition, in contrast to fast-proliferating tumor cells, in RA only limited amounts of synovial cells, and therefore limited amounts of mRNA, can be obtained for molecular analysis. Therefore, the cells are often grown over several passages to obtain sufficient cellular material to perform the required experiments. In this situation, it is frequently difficult to know whether the cell population after an extended cultivation time is still identical to the RASF population shortly after isolation from the tissue. Moreover, passaging may result in a selection pressure for parts of the cell population, for example adherent cells vs. trypsin-sensitive cells, that are being removed to a different extent from the culture flask during passaging and that may alter the overall gene expression profile in higher passages and lead to different results when compared with earlier passages.

To evaluate whether cell culture effects take place in RASF cultures over several passages, we performed cDNA array analysis for up to nine passages. Early passages were compared with later passages to evaluate alteration of gene expression as consequence of cell culture in detail. In addition, the proliferation rate was measured by the doubling time of the population over the passaging time of the cells to evaluate changes in cell growth rates in comparison to earlier passages.

\section{Materials and methods}

\section{Synovial tissue and cell culture}

Synovial tissues were obtained from synovial biopsies of six patients with RA undergoing joint surgery (synovectomy or joint replacement by prosthesis implantation), who all met the criteria of the American College of Rheumatology [27]. The tissue samples were obtained during routine surgery at the Department of Orthopedics of the University of Regensburg, where approved by the local ethics committee and patients involved gave informed consent. Culture of SF was performed as described recently [5]. Following enzymatic digestion, fibroblasts were grown in DMEM (Biochrom, Berlin, Germany) containing $10 \%$ heat inactivated FCS (Gibco Life Technologies, Grand Island, NY, USA), $100 \mathrm{U} / \mathrm{ml}$ penicillin and streptomycin (PAA Laboratories $\mathrm{GmbH}$, Linz, Austria) and cultured for four passages at $37^{\circ} \mathrm{C}$ in $10 \%$ carbon dioxide. The SF were stained for a fibroblast marker by immunohistochemistry. More than 95\% could be stained positively for the fibroblast enzyme prolyl 4-hydroxylase and none were positive for the macrophage marker CD68 or the neutrophil marker cathepsin $G$ after the second passage of cultivation with enzymatic digestion equalling passage 0 (data not shown). Routine tests for mycoplasms were negative. At 85 to $95 \%$ confluency, cells were passaged 1:2 and a part of the cells was harvested. Total RNA was extracted and stored at $-70^{\circ} \mathrm{C}$. Culture conditions were (and have to be) kept constant during the experiments. Passaging of the cells was performed at 85 to $95 \%$ confluency as fibroblasts exhibit contact inhibition (unpublished observations) and were passaged 1:2 to provide cell-cell contacts between the cells.

\section{Cell culture proliferation measurement}

After enzymatic digestion of the tissue (passage 0), the cells were grown to 85 to $95 \%$ confluence, then trypsinized, counted and 50,000 cells were seeded into five fresh cell culture six-wells (passage 1). Each day, one well was trypsinized and the cells were counted. The day at which the double cell number $(>100,000)$ occurred was noted. At 85 to $95 \%$ confluency, this procedure was repeated (passage 3 ) until passage 8 . The doubling time in days was determined as 'doubling point', when the cells doubled their number $(100,000)$ as compared with the day they were counted $(50,000)$ and seeded.

\section{Storage of cells in liquid nitrogen}

For evaluation of the effects of freezing, that is storage in liquid nitrogen, cells in passage 1 (the passage after enzymatic digestion) were trypsinized, centrifuged and resuspended in FCS with 10\% DMSO (dimethyl sulfoxide) (v/ v) in a $1 \mathrm{ml}$ cryovial. Cells were immediately stored on ice, placed in a freezer and frozen over night at $-80^{\circ} \mathrm{C}$ (freezing speed about $\left.1^{\circ} \mathrm{C} / \mathrm{min}\right)$. Thereafter, cells were directly transferred to liquid nitrogen.

To thaw the cells, the cryovials were carefully thawed at $37^{\circ} \mathrm{C}$, the cell suspension transferred into preheated $\left(37^{\circ} \mathrm{C}\right)$ culture medium and centrifuged to remove the DMSO. It was resuspended in culture medium and then transferred into cell culture flasks and cultured (passage 2 for the cells after cryostorage) and passaged for up to six passages under standard conditions as outlined above.

\section{RNA extraction}

Total cellular RNA was extracted from human fibroblasts using the RNeasy spin column purification kit (Qiagen, Hilden, Germany). To remove contaminating genomic DNA, total RNA was treated with DNase I $(0.2 \mathrm{U} / \mu \mathrm{l}$; Boehringer Mannheim, Mannheim, Germany) for 40 minutes at $37^{\circ} \mathrm{C}$. RNA concentrations were measured using the Ribogreen RNA quantification kit (Molecular Probes, Leiden, the Netherlands), adjusted to $200 \mathrm{ng} / \mu \mathrm{l}$ in 
water and stored at $-70^{\circ} \mathrm{C}$. Equal aliquots were then electrophoresed on $1 \%$ agarose gels stained with ethidium bromide to compare large and small rRNAs qualitatively and to exclude degradation. When starting with fresh RNAs, one RNA arbitrarily primed(RAP)-PCR was performed (details see below) without the reverse transcriptase as a control for DNA contamination.

\section{RNA arbitrarily primed PCR of total cellular RNA}

RAP-PCR of total cellular RNA was performed as described previously $[6,11,22]$. As a template for each experiment, 250 ng of RNA was used. First-strand synthesis was carried out using MuLV (Moloney murine leukemia virus) reverse transcriptase (Promega, Madison, WI, USA) and $2 \mu \mathrm{M}$ first strand arbitary primer. Second strand synthesis was performed in a $20 \mu \mathrm{l}$ reaction using AmpliTaq Stoffel Fragment (Perkin Elmer, Norwalk, CT, USA), $2.8 \mu \mathrm{l}[\alpha-32 \mathrm{P}] \mathrm{dATP}(3,000 \mathrm{Ci} / \mathrm{mmol}, 10 \mathrm{mCi} / \mathrm{ml})$, and $4 \mu \mathrm{M}$ arbitrary second primer. Subsequently, the reaction was cycled through 30 low stringency cycles (30 seconds $94^{\circ} \mathrm{C}, 30$ seconds $35^{\circ} \mathrm{C}, 30$ seconds $72^{\circ} \mathrm{C}$ ). Primer combination for RAP-PCR was: OPN23 (5'-CAG GGG CAC C-3') for first strand and OPN21 (5'-ACC AGG GGC A-3') for second strand synthesis.

\section{Atlas $^{\mathrm{Tm}} \mathrm{CDNA}$ expression array}

Two different AtlasTM human cDNA expression array membranes (Clontech, Palo Alto, CA, USA) containing the human cDNAs were used: The Atlas Human Cancer cDNA Expression Array and the Atlas Human Oncogene cDNA Expression Array. From each of these genes, cDNA was amplified using RAP-PCR as described recently $[10,11]$.

\section{Preparation of CDNA probes}

The PCR products were purified from unincorporated 32P-labeled nucleotides and small cDNA fragments $(<0.1$ kb) by column chromatography using NucleoSpin Extraction Kit (Clontech, Palo Alto, CA, USA) as outlined by the producer. A total volume of $100 \mu \mathrm{l}$ was used for hybridization. A $2 \mu \mathrm{l}$ sample of the purified probe was measured by scintillation counting.

\section{Hybridization}

The cDNA was hybridized to the Atlas ${ }^{\mathrm{Tu}}$ human cDNA expression array membranes in roller bottles. The filters were transferred to roller bottles and prehybridized in 5 $\mathrm{ml}$ prewarmed $\left(68^{\circ} \mathrm{C}\right)$ hybridization solution (ExpressHyb Hybridization Solution, Clontech, Palo Alto, CA, USA) with $100 \mu \mathrm{g} / \mathrm{ml}$ fragmented denatured salmon sperm DNA in a hybridization oven. The labeled cDNA probe was diluted 1:10 with 10 times denaturing solution (1M NaOH, $10 \mathrm{mM}$ EDTA) and incubated at $68^{\circ} \mathrm{C}$ for 20 minutes. A $5 \mu \mathrm{l}(1 \mu \mathrm{g} / \mu \mathrm{l})$ sample of sheared human genomic DNA was added with an equal volume of two times neutralizing solution $\left(1 \mathrm{M} \mathrm{NaH}_{2} \mathrm{PO}_{4}, \mathrm{pH} 7.0\right)$ and incubated for 10 minutes at $68^{\circ} \mathrm{C}$. The mixture was added to the filters with the hybridization solution and hybridized over night.

\section{Wash}

The filters were washed three times in wash solution 1 (2 $\times$ SSC (saline sodium citrate) and 2\% SDS) for 30 minutes at $68^{\circ} \mathrm{C}$ each. Two washing steps were performed with wash solution $2(0.1 \times \mathrm{SSC}$ and $0.5 \% \mathrm{SDS})$ at $68^{\circ} \mathrm{C}$ for 20 minutes and one step for five minutes at room temperature in $2 \times$ SSC and then exposed to a Phosphor-ImagerScreen (Molecular Dynamics, Sunnyvale, CA, USA) for three to five days depending on the intensity of radiation of the bound fragments. Data analysis was performed using the Ambis software (ImageQuant, Molecular Dynamics, Sunnyvale, CA, USA). Evaluation was performed using the AtlasImage ${ }^{\mathrm{mm}} 2.7$ software, developed specifically for analysis of the Atlas ${ }^{\mathrm{mm}}$ cDNA Expression Arrays (Clontech, Palo Alto, CA, USA [28]). Data comparison data have been deposited in the NCBI GEO database with the series record access number [GEO:GSE21385].

\section{Array comparison and statistical evaluation}

To compare arrays of different hybridizations using the Atlas $^{\mathrm{mu}}$ array system, background and signal intensity need to be normalized. The default signal threshold determined by the software was used and kept constant for all analyses. After background correction of the arrays, the median signals for all spots on an array were used to calculate the correction coefficient (global normalization), which demonstrated to be the most reliable method for the AtlasImage 2.7 software for our array settings [28].

Statistical evaluation for multiple array comparison was performed using Lavene-test followed by $t$-test (parametric) or by Mann-Whitney U test (non-parametric), with significance level correction according to the number of compared genes (Bonferroni adjustment) as described previously [28]. For 100 comparisons, a random significance of $P<0.05$ in 5 of 100 comparisons occurs ( $\alpha$-Factor). Therefore, the significance level was adjusted: $P=$ $0.05 / \mathrm{n}_{\text {comparisons }}$ (e.g for 100 comparisons the new significance level is $P<0.0005)$. Only genes that reached the statistical significance level after Bonferroni-correction were regarded as being differentially expressed.

\section{Real-time PCR}

Real-time PCR was performed using a LightCycler system (Roche Diagnostics, Mannheim, Germany). Reactions were performed in a $20 \mu \mathrm{l}$ volume with $0.5 \mu \mathrm{M}$ primers; CD82 for 5'-TAT GTC TTC ATC GGC GTG GG-3'; CD82 rev 5'-CAT GAG CTC AGC GTT GTC TG3'; c-myc for 5'-CTA TGA CCT CGA CTA CGA CT-3'; c- 
myc rev 5'-CGC AGA TGA AAC TCT GGT TC; $18 \mathrm{~S}$-for 5'-TCA AGA ACG AAA GTC GGA G-3'; 18S-rev: 5'GGA CAT CTA AGG GCA TCA CA-3'), $3 \mathrm{mM} \mathrm{MgCl}_{2}$ concentration, and $2 \mu \mathrm{l}$ LightCycler-FastStart Reaction Mix SYBR Green I (Roche Diagnostics, Mannheim, Germany). After 10 minutes polymerase activation at $95^{\circ} \mathrm{C}$, 40 cycles with $95^{\circ} \mathrm{C}$ for 15 seconds, $52^{\circ} \mathrm{C}$ for 5 seconds and $72^{\circ} \mathrm{C}$ for 20 seconds were performed. Fluorescence was measured at the end of the $72^{\circ} \mathrm{C}$ extension period. Efficiencies of the primers were tested using the standard curve method ( $\left.\mathrm{E}=10^{-1 / \text { slope }}\right)$. According to the guidelines of the manufacturer, efficiencies of $2.00 \pm 0.05$ were considered acceptable for experiments. To confirm amplification specificity, the PCR products were subjected to a melting curve analysis to exclude primer dimers and nonspecific amplification. Data were analyzed using the LightCycler analysis software (Roche, Mannheim, Germany). The baseline of each reaction was equalized by calculating the mean value of the five lowest measured data points for each sample and subtracting these values from each reading point. Background fluorescence was removed by setting a noise band. In this setting, the number of cycles at which the best-fit line through the log-linear portion of each amplification curve intersects the noise band is inversely proportional to the log of copy numbers.. The crossing points $(\mathrm{CP})$ are the intersections between the best fit lines of the log-linear region and the noise band. The CP determined for the respective genes were normalized to those of $18 \mathrm{~S}$ RNA to compensate for variabilities in the amount of RNA and for exclusion of general transcriptional effects.

\section{Results}

\section{Expression of genes in RASF during cell culture passaging}

For each RA patient, the isolated SF cell population was passaged in two independent experiments. RNA was extracted and cDNA array experiments were performed. The cDNA arrays were subsequently hybridized with radioactive labeled cDNA probes from the different passages of the RA patients (Figure 1). Expression patterns of RASF in early passages in comparison to higher passages was performed for each patient individually $(n=4)$ and the alteration in percentage was calculated and compared for the four patients (Figure 2). Only genes, that reached the signal threshold, were constant in the repeated experiments, and reached the statistical significance level after Bonferroni-correction as described were regarded as differentially expressed.

The gene expression patterns of the RASF populations were constant in all patients during passages 1 to 4 (about $7 \%$ difference in gene expression; Figure 2), and one patient showed even a constant gene expression for up to five passages (data not shown).
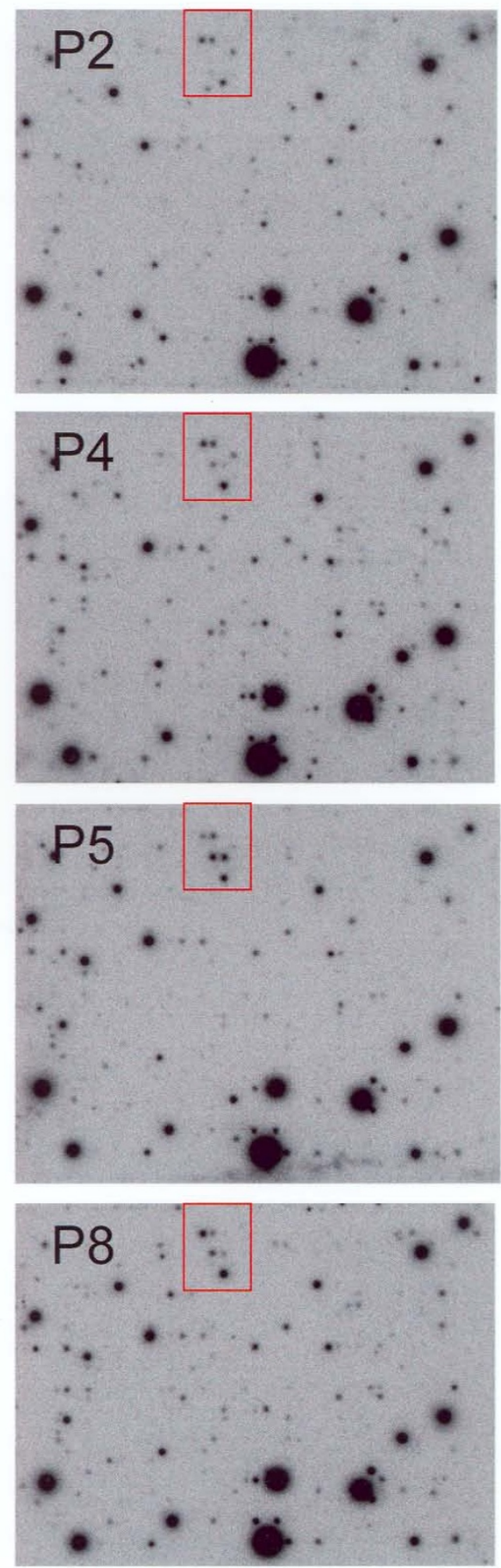

Figure 1 Expression patterns of genes in RASF during the different cell culture passages. Example for CDNA arrays of the rheumatoid arthritis synovial fibroblasts (RASF) in different passages from one RA patient. Sections of the Atlas Human Cancer cDNA Expression Arrays are shown. (a) Passage 2, (b) passage 4 with mostly constant expression when compared with passage 2, (c) passage 5 with changes about $7 \%$ of the expressed genes when compared with passage 2 , and (d) passage 8 with changes about $10 \%$ of the expressed genes when compared with passage 2. p, passage. 

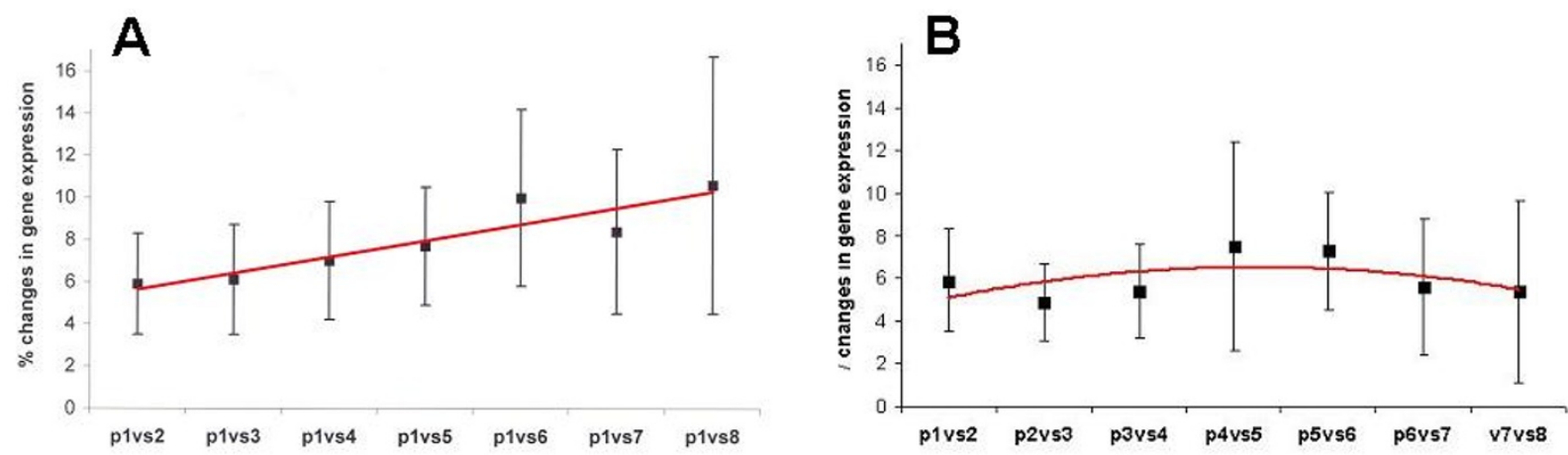

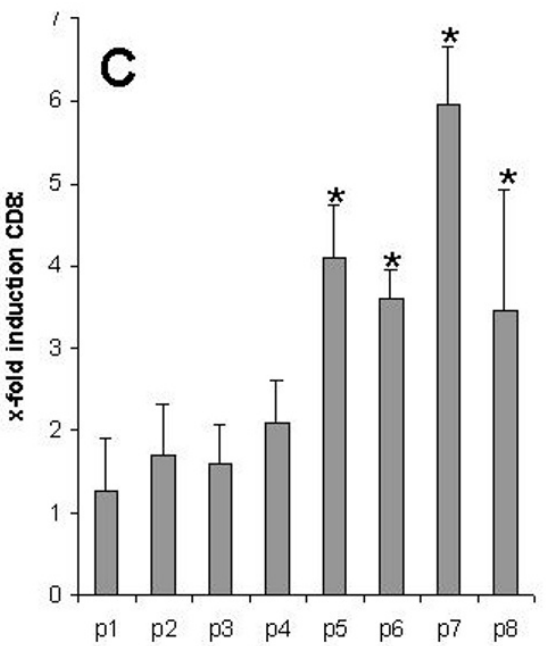

RA 3

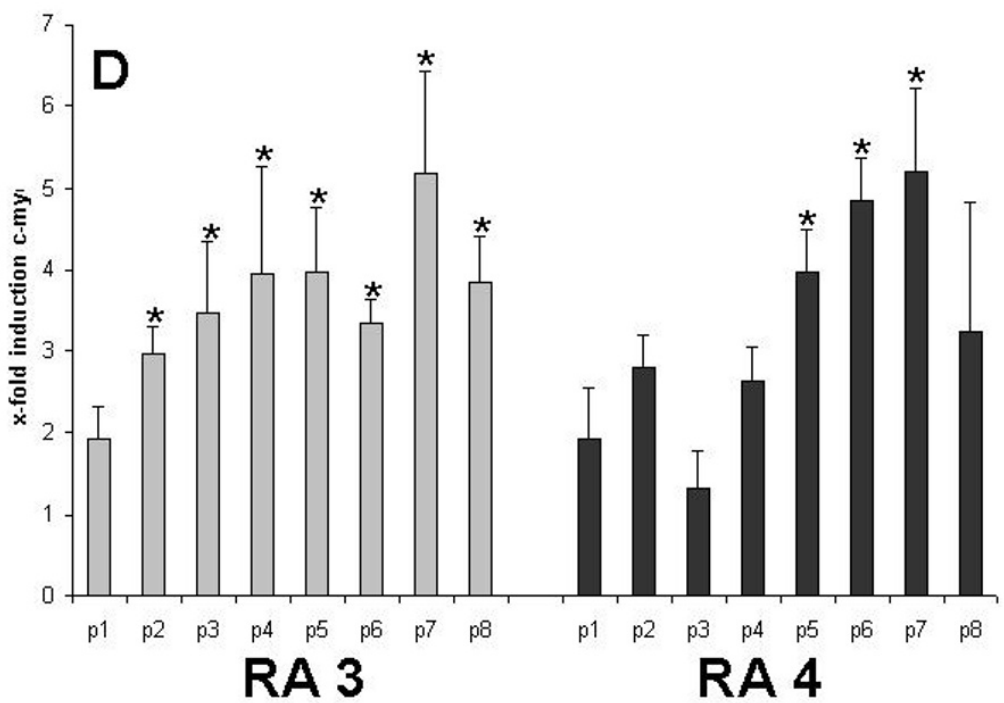

Figure 2 Changes in gene expression during passaging. (a) The changes in gene expression increase substantially during passaging of the cells in all fibroblast cultures. In addition, the variations and differences between expression pattern in the different rheumatoid arthritis synovial fibroblasts (RASF) cultures increase also in later passages (\% changes of gene expression \pm standard error of the mean). The regression line shows a clear increment in the course of the culture of the cells (red). (b) Changes in gene expression comparing higher passages instead of passage 1. (c) Verification of CD82 and c-myc regulation using real-time PCR. Passaging was performed in two parallel cultures for each fibroblast population. Real-time PCR was performed threefold (six measurements for each population, respectively).

Of note, passage 0 , which is the first culture of adherent cells after enzymatic digestion (after removing of the non-adherent cells and the supernatant and after several washing steps) differed in the expression pattern to each of the passages 1 to $9(>10 \%)$, indicating that contaminating cells such as macrophages and endothelial cells are, as expected from immunocytochemistry, present at passage 0 (data not shown). In detail, the variation of two parallel cultures of the same RASF populations showed a differential gene expression of below $1 \%$ of the expressed genes.

Substantial changes of gene expression in the RASF populations could be detected after passages 5 to 6 . They varied individually for the different patients resulting in alteration of about 7 to $10 \%$ of the analyzed genes (Figure 2a). After passages 7 to 8 , more than $10 \%$ of the analyzed genes could be found to be differentially expressed (Fig- ure 2a). The increase in expression changes, altered during passaging, are constant through the passages (Figure $2 \mathrm{~b})$. When comparing higher passages with passage 2 instead of passage 1, the same increase of expression changes in percentage could be detected (regressionline in Figures 2a and 2b).

Interestingly, the genes that were differentially expressed at later passages were not identical in the different passages, thus underlining the observation that the gene expression pattern starts to be inconstant and diverging in later passages (data not shown). To visualize the changes between the passages, intensities of the arrays compared (after background correction) are presented for one exemplary passage comparison (Figure 3). In addition to the comparisons between early passages (passage 1) and higher passages, the graphs for comparisons between higher passages are also presented. Of note, 
the differences between the higher passages (e.g. passage 6 to 7) show a more constant pattern then when compared with very early passages (e.g. passage 1 to 7). Altered genes included, for example, oncogenes, cytokines, and proliferation-associated genes, but no specific gene groups were differentially expressed in all patients and all experiments. Examples of the regulated genes and gene groups are listed in Table 1. The list of regulated genes is available at the Arthritis Research and Therapy homepage. Here, the genes are presented, in which the differential expression starting in a defined passage reaches statistical significance and differential expression continues through passaging of the cell population (>'passage). In addition, two genes were verified using real-time PCR (c-myc oncogene, CD82), indicated with ** for the RA SF populations tested in Figure 2c. Only genes that reached the signal threshold, were constant in the repeated experiments, and reached the statistical significance level after Bonferroni-correction as described were stated as differentially expressed. Some of the presented genes are highlighted in Figure 3, to illustrate the constancy between the passages in one exemplary fibroblast population. The data reflect, in part, the slowed cell cycling and reduced proliferation, as most of the regulated genes could be related to this process. But also other genes, such as cytokine receptors and regulators of other cellular pathways are altered during passaging (Table 1).

\section{Expression of genes in RASF after storage in liquid nitrogen} The cDNA arrays were subsequently hybridized with radioactive labeled cDNA probes from freshly cultured RASF for up to six passages after thawing of the cells. Expression patterns of the thawed then cultured RASF were compared with the freshly cultured cells (with passage 1 as baseline for constant gene expression basis) as shown in Figure 4. The changes in the gene expression pattern after thawing were similar to the not frozen cells (Figure 2a), and the first passage after thawing (passage 2)

Table 1: Genes, that are differentially expressed during cell culture

\begin{tabular}{|c|c|c|c|c|c|c|c|c|c|}
\hline \multirow{2}{*}{$\begin{array}{l}\text { Gene group } \\
\text { Cytokines/-receptors }\end{array}$} & \multirow{2}{*}{$\begin{array}{l}\text { Regulated genes } \\
\text { TNF receptor } 1\end{array}$} & \multicolumn{2}{|c|}{ RA-1 } & \multicolumn{2}{|c|}{ RA-2 } & \multicolumn{2}{|c|}{ RA-3 } & \multicolumn{2}{|c|}{ RA-4 } \\
\hline & & 3 & $\downarrow$ & $5-8$ & $\uparrow$ & 5 & $\uparrow$ & $3-8$ & $\uparrow$ \\
\hline & MCSF I receptor precursor & 6,8 & $\uparrow$ & $6-8$ & $\downarrow$ & 2 & $\downarrow$ & $5-8$ & $\downarrow$ \\
\hline & epidermal growth factor receptor 1 & 3,4 & $\uparrow$ & - & & $6-8$ & $\uparrow$ & $4-8$ & $\uparrow$ \\
\hline & insulin-like growth factor I receptor & $>5$ & $\uparrow$ & 3,7 & $\uparrow$ & $7-8$ & $\uparrow$ & $5,6,8$ & $\uparrow$ \\
\hline Adhesion & ILK & $>5$ & $\downarrow$ & 2 & $\uparrow$ & 2,6 & $\uparrow$ & $4-8$ & $\downarrow$ \\
\hline \multirow[t]{2}{*}{ Apoptosis } & $\begin{array}{l}\text { Fas-activated serine/threonine kinase } \\
\text { cytotoxic TRAIL receptor } 2 \text { (DR 5) }\end{array}$ & $4-8$ & $\uparrow$ & $7-8$ & $\uparrow$ & 6 & $\uparrow$ & $6-8$ & $\uparrow$ \\
\hline & & $5-8$ & $\uparrow$ & 2 & - & $7-8$ & $\downarrow$ & 8 & $\uparrow$ \\
\hline \multirow[t]{5}{*}{ Proliferation } & tumor suppressor LUCA1 & $6-8$ & $\uparrow$ & $7-8$ & $\uparrow$ & $7-8$ & $\uparrow$ & 6,8 & $\uparrow$ \\
\hline & p33ING1 & $4-8$ & $\uparrow$ & $6-8$ & $\uparrow$ & $3-8$ & $\uparrow$ & $3-8$ & $\uparrow$ \\
\hline & p53 cellular tumor antigen & $4-8$ & $\uparrow$ & 6,8 & $\uparrow$ & 3,7 & $\uparrow$ & $7-8$ & $\uparrow$ \\
\hline & cyclin-dependent kinase inhibitor $1 \mathrm{C}$ & $6-8$ & $\uparrow$ & 2 & $\uparrow$ & $4-8$ & $\uparrow$ & - & \\
\hline & ski oncogene & $7-8$ & $\uparrow$ & 4 & $\uparrow$ & 6,7 & $\uparrow$ & 6,8 & $\uparrow$ \\
\hline Proliferation/Signaling & shb proto-oncogene & $4-8$ & $\downarrow$ & $7-8$ & $\downarrow$ & - & & 2 & $\downarrow$ \\
\hline \multirow[t]{5}{*}{ Signaling } & notch2 & $5-8$ & $\uparrow$ & 6 & $\uparrow$ & $5,6,8$ & $\downarrow$ & 5 & $\downarrow$ \\
\hline & jun-B & $7-8$ & $\uparrow$ & $4,5,7,8$ & $\uparrow$ & $5-8$ & $\uparrow$ & 4,7 & $\uparrow$ \\
\hline & frizzled & $7-8$ & $\uparrow$ & 8 & $\uparrow$ & 2 & $\uparrow$ & 8 & $\uparrow$ \\
\hline & FRA2 & $3-8$ & $\downarrow$ & $7-8$ & $\downarrow$ & $5-7$ & $\downarrow$ & 2 & $\uparrow$ \\
\hline & NOTCH1 precursor & $5-8$ & $\uparrow$ & 5 & $\uparrow$ & 4,5 & $\uparrow$ & $7-8$ & $\uparrow$ \\
\hline \multirow[t]{4}{*}{ Others } & semaphorin 1 & $7-8$ & $\uparrow$ & - & & $4-8$ & $\downarrow$ & 3,4 & $\uparrow$ \\
\hline & glycogen synthase kinase 3 alpha & $6-8$ & $\uparrow$ & 6 & $\uparrow$ & $5-8$ & $\uparrow$ & $3-8$ & $\uparrow$ \\
\hline & thymosin beta-10 & $5,6,8$ & $\downarrow$ & $4,6,7$ & $\downarrow$ & $7-8$ & $\uparrow$ & $5-8$ & $\uparrow$ \\
\hline & ezrin; cytovillin 2; VIL2 & $7-8$ & $\downarrow$ & $4-8$ & $\downarrow$ & 4 & $\uparrow$ & 5 & $\downarrow$ \\
\hline
\end{tabular}

Exemplary gene groups and genes and their regulations are shown. Only genes, that reached the signal threshold and the statistical significance level after Bonferroni-correction as described in methods were regarded as differentially expressed $(P<0.00025)$.

FRA2: fos-rrelated antigen 2; ILK: integrin-linked kinase; MCSF: macrophage colony-stimulating factor; RA: rheumatoid arthritis; TRAIL: tumor necrosis factor related apoptosis inducing ligand; VIL2: villin 2. 
(A)

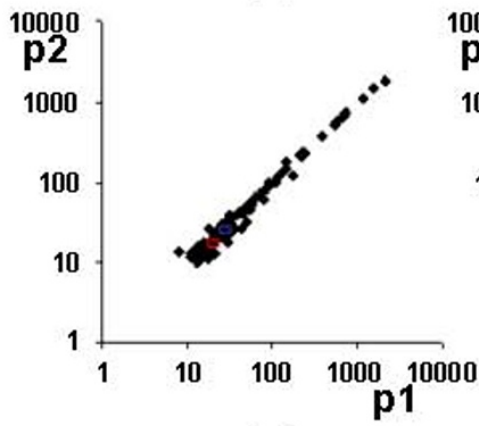

(D)

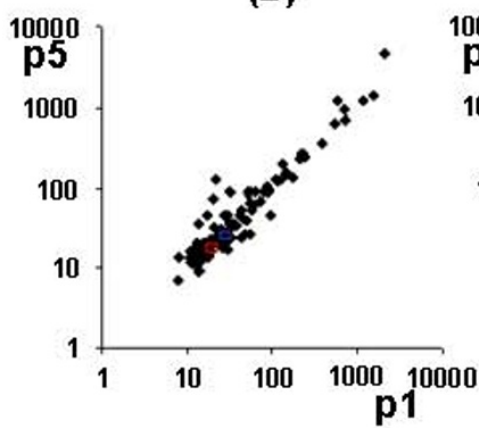

(G)

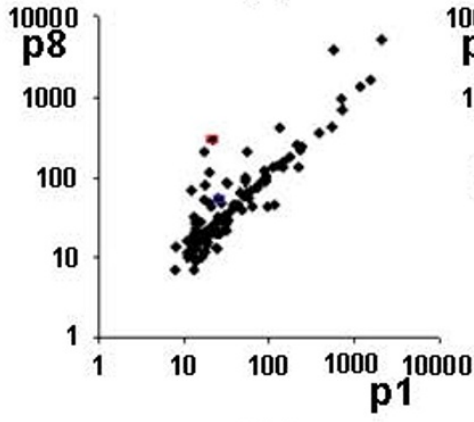

(J)

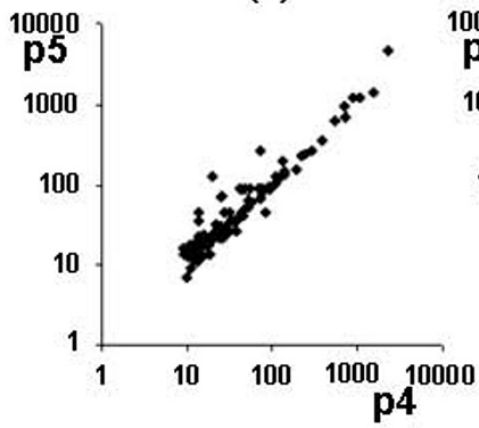

(B)

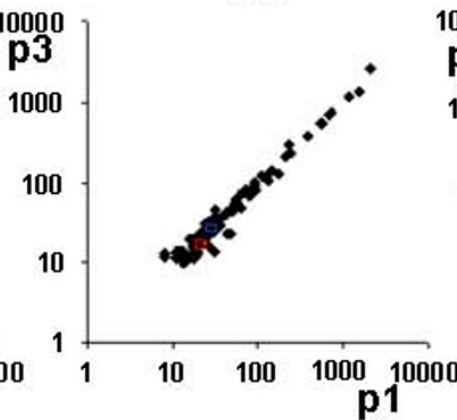

(E)
(C)

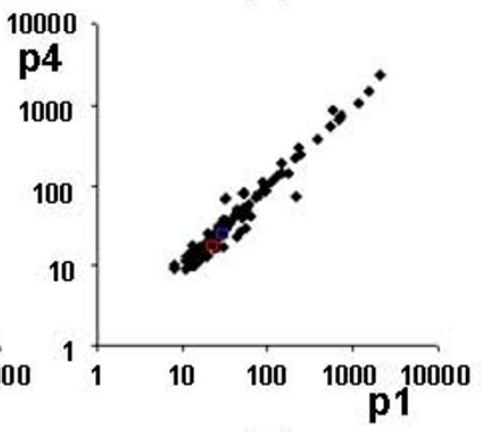

(F)

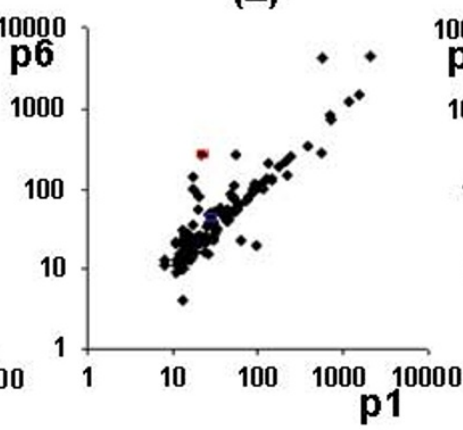

(H)

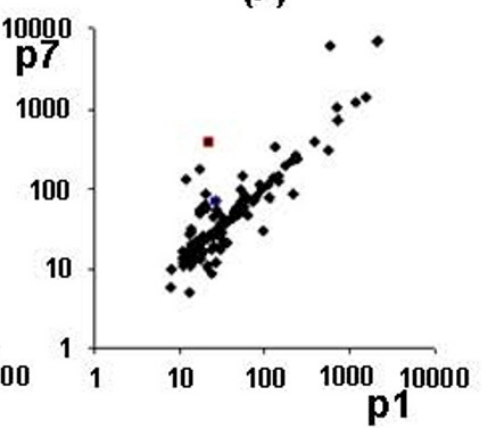

(I)

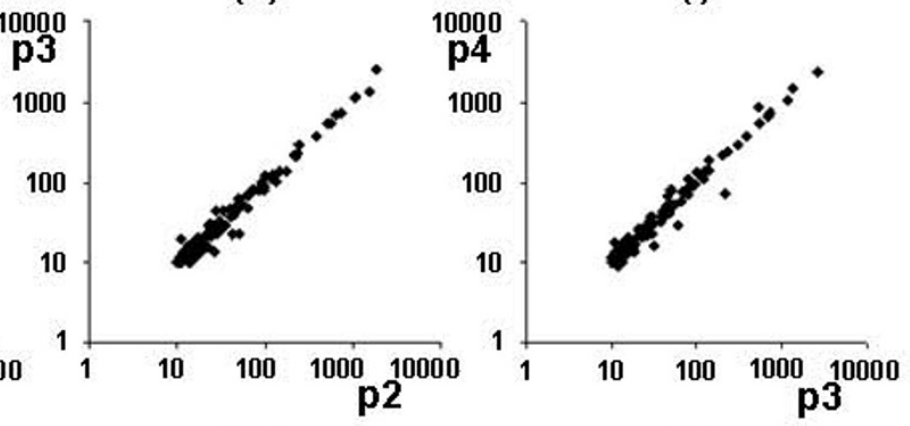

(L)
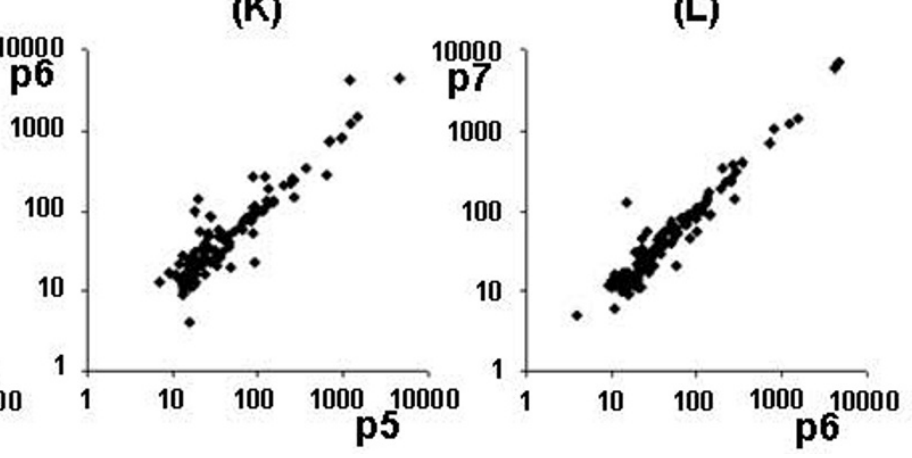

Figure 3 Changes in gene expression. Results are presented for one rheumatoid arthritis (RA) patient using an Atlas Human Cancer cDNA Expression Array for direct comparison of the relative intensities of the compared passages, showing strong variations at higher passages in this example. (a to g) Passage 1 was compared with higher passages. Examples of two genes are presented. In red: Expression of c-myc. In blue: expression of p33ING1 during culture of the exemplary RA synovial fibroblasts (SF) population. (h to I) In addition, higher passages are compared with each other showing the differential expression pattern between higher passages. 
showed more changes in gene expression when compared with passage 3 (Figure 4). Substantial changes of gene expression in the RASF populations could be detected in passages 5 to 6 with alterations from 9.5 to $12.0 \%$ of the expressed genes (Figure 4).

\section{Proliferation of RASF during cell culture passaging}

The cell doubling rate was measured during passages 1 to 8 as described above by counting the cells each day (parallel experiments with equal cell numbers per well as described in methods). The day after the passaging of the cells in which the cell number doubled after passaging was noted for each passage. Interestingly, a constant doubling rate was found in the early passages 3 to 4 and in most patients in passage 5 ( $4 \pm 1$ day), which increased during the further cultivation of the cells (passages 6 to 8). At later passages the doubling rate was increased up to seven days, indicating that the 'older' cell populations show a decreased proliferation rate (Table 2 and Figure 5).

\section{Discussion}

T-cell independent pathways, such as upregulation of proto-oncogenes, production of growth factors and the release of matrix-degrading enzymes lead to progressive destruction of the affected joints [2,15]. Transformedappearing, activated SF are key players in this synovial activation $[1,2,5]$. To identify the underlying mechanisms of the destructive behavior of RASF, in vitro cultured RASF are used in various experimental settings $[10,11,13-15]$. The analysis of the pathways that may help to understand the progressive growth at the invasion

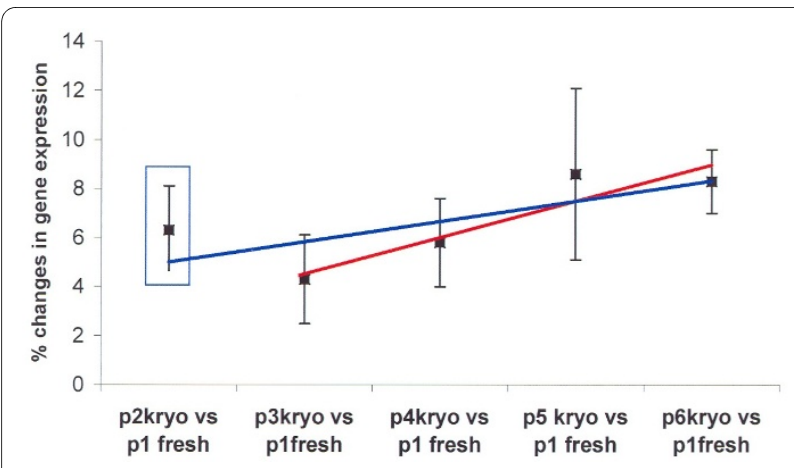

Figure $\mathbf{4}$ Changes in gene expression after storage in liquid nitrogen. The changes in gene expression after thawing the cells and culturing for up to six passages were compared with the freshly cultured cells with passage 1 as baseline for the comparison. The blue regression line shows the values for passage 2 to 6 after thawing of the cells when compared with passage 1 of the freshly cultured cells, including passage 2 (blue square). The red regression line shows the values for the passages 3 to 6 without the first passage after thawing of the cells (excluding the value in the blue square), showing that the passage immediately after thawing showes higher values of differentially expressed genes due to the thawing procedure. p, passage. zone and the active cartilage and bone degradation without interfering with physiologic matrix remodeling is therefore mandatory to identify novel therapeutic targets to inhibit the progressive joint destruction by RASF.

Several cytogenetic and molecular biology techniques are currently used to identify differentially expressed genes under different biological conditions, for example differential display, subtractive hybridization, and cDNA arrays $[9,11,13,19,29]$. They are currently used to analyze molecular changes and mechanisms involved in the pathogenesis of RA [9-11,30-32]. The advantages of the current techniques include analysis of gene subsets, comparison of more than two biological conditions in combination with a high sensitivity. In additon, to control the effects of potential new drug targets such as proliferation inhibitors, antiinflammatory and destruction inhibiting molecules, in vitro analysis using RASF or animal models including the use of human RASF such as the SCID mouse model for RA are helpful tools $[9,10,18,25,26,32,33]$. Unfortunately, high amounts of cellular material (mRNA or protein) are required in most cases for the different gene or gene product analysis.

To evaluate the critical effects of this passaging procedure in cell culture on gene expression, RASF were therefore cultured over several passages followed by cDNA array analysis for up to eight passages and comparison of early passages to higher culture passages was performed. In addition, the effects of the storage of RASF in liquid nitrogen on gene expression were examined.

As shown in Figure 2, the gene expression pattern of the RASF populations were constant at passages 2 to 4 . Passage 0 was different when compared with passages 1 to $8(>10 \%)$, which is most likely due to the presence of macrophages on the culture plate (detectable by immunohistochemistry $[1,5]$ ), which are not present at the later passages 1 to 8 . In addition, changes in gene expression of RASF populations could be detected after passages 5 to 6 , showing changes of 7 to $10 \%$ of the analyzed genes (Figure 2). After passages 7 to 8 , more than $10 \%$ of the analyzed genes were differentially expressed combined with an increasingly inconstant expression pattern at higher passages.

Thawing of the cells after storage in liquid nitrogen affected mainly the gene expression of the first passage of the cells, possibly due to the stress of thawing and the remaining DMSO until the DMSO was completely removed. Thereafter, the cells showed a similar pattern of gene expression when compared with the freshly cultured RASF as the non-frozen cells (Figures 2 and 3). Moreover, the proliferation rates of the fibroblast cultures decreased in later passages, showing a decreased doubling rate after five to eight passages (Table 2).

Taken together, the data of the study show that experiments, which involve analysis of gene expression and the 
Table 2: Cell doubling rates (in days) during cell culture passages for each patient

\begin{tabular}{lllllllll}
\hline Patient & p1 & p2 & p3 & p4 & p5 & p6 & p7 & p8 \\
\hline RA-1 & 3 & 4 & 3 & 5 & 5 & 6 & 5 & 7 \\
RA-2 & 4 & 3 & 4 & 4 & 4 & 4 & 5 & 6 \\
RA-3 & 4 & 4 & 3 & 4 & 4 & 5 & 6 & 7 \\
RA-4 & 4 & 4 & 4 & 3 & 4 & 6 & 6.25 & 6.5 \\
Mean & 3.75 & 3.75 & 3.5 & 4.0 & 4.25 & 5.25 & 0.5 \\
\pm SD & 0.43 & 0.43 & 0.50 & 0.71 & 0.43 & 0.83 & 0.50 \\
\hline
\end{tabular}

The cell doubling rate was measured by counting the cells. The day, the cell numbers were doubled after passaging of the cells is listed for each passage.

p: passage; RA: rheumatoid arthritis; SD: standard deviation.

phenotype of RASF, should be limited to early cell culture passages, that is passages 2 to 5 , to avoid cell culture effects, diverging gene expression at higher passages, and decreased proliferation of the analyzed RASF populations. In case of a need for larger cell numbers, for example for transduction or animal experiments, an internal long-term cultivation control should be performed, which also includes the comparison of early passaged cells to later passaged cells. In addition, storage of cells in liquid nitrogen affect mainly gene expression of the first culture passage after thawing of the cells and therefore, the second passage should be used for experiments.

Therefore, this paper addresses researchers who perform experimental approaches with cultured SF on the RNA expression level. We want to highlight that culturing of the cells for a too high number of passages will produce differences in gene expression in comparison to the cells used at low passages. Many researchers address the ability to proliferate, the induction of apoptosis and the cytokine expression by these experiments. The intention of the paper is not to recommend excluding culturing

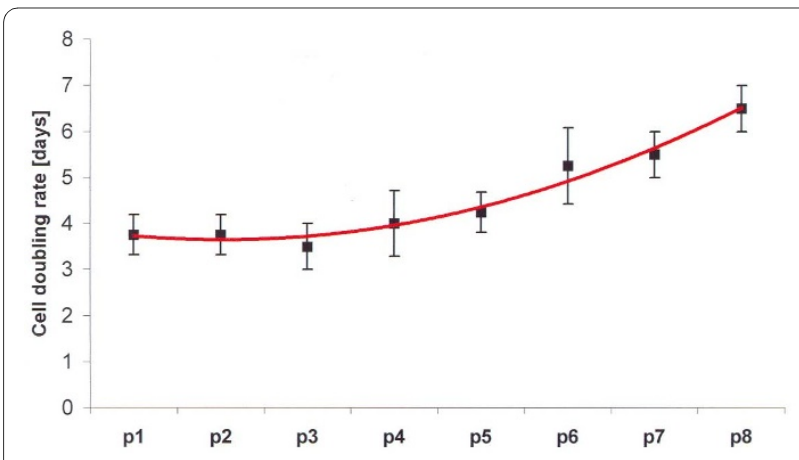

Figure 5 Cell doubling rates (in days) during cell culture passages for each patient. The cell doubling rate was measured by counting the cells. The day, the cell numbers were doubled after passaging of the cells was noted for each passage. The tendency shows a constant doubling rate in early passages, which increases during the cultivation of the cells. p, passage.
RASF after four or five passages, but to keep the problems of culturing in mind to avoid false-positive results and additional, rather labor-consuming, work when verification of the obtained expression data with fresh cell cultures is performed. Culture conditions should be kept constant during the experiments. In addition, we want to emphasize, that the functional ability of the cells or the regulation on protein level are not necessarily changed.

\section{Conclusions}

The increased potential of high-resolution molecular analysis techniques for evaluation of cultured synovial cells, not only reveals the effects of culture on gene expression, it also illustrates the mandatory duty to take these effects into account when simulating the in vivo situation with an in vitro setting.

\section{Abbreviations}

CP: crossing points; DMEM: Dulbecco's modified eagle medium; FCS: fetal calf serum; RA: rheumatoid arthritis; RAP-PCR: RNA arbitrarily primed PCR; SCID: severe combined immunodeficient mice; SF: synovial fibroblasts.

\section{Competing interests}

The authors declare that they have no competing interests.

\section{Authors' contributions}

EN was involved in the experiment organization, design, and performance writing, design and structure of the paper. BR performed part of the experiments. AK was involved in the evaluation and interpretation of data. SL was involved in evaluation and interpretation of data. IHT was involved in evaluation and interpretation of data. JG was involved in preparation of the synovial tissue for RASF isolation. JSt was involved in preparation of the synovial tissue for RASF isolation. SG was involved in evaluation and interpretation of data. JSC was involved in evaluation and interpretation of data, structural organziation of the paper. UML was involved in experimental design and organization, paper design and structure. All authors read and approved the final manuscript.

\section{Acknowledgements}

This study was supported by grants of the German Academic Research Society (DFG \# Mu 1383/1-3, 1383/3-4 as well as the SNF-3200-64142.00). The authors are indebted to Wibke Ballhorn, Birgit Riepl, and Olga Wiesner for excellent technical assistance. 


\section{Author Details}

1Department of Internal Medicine and Rheumatology, University of Gießben, Kerckhoff-Klinik, D-61231 Bad Nauheim, Benekestr. 2-8, Germany, 2Department of Internal Medicine I, University of Regensburg, D-93042 Regensburg, Franz-Joseph-Strauß-Allee 11, Germany, ${ }^{3}$ Department of Orthopedics, University of Regensburg, D-93042 Regensburg, Franz-JosephStrauß-Allee 11, Germany, ${ }^{4}$ Department of Orthopedics, Laboratory of Experimental Orthopedics, University Hospital of Giessen and Marburg, D35392 Giessen, Paul Meimberg Str. 3, Germany and ${ }^{5}$ Center for Experimental Rheumatology, Department of Rheumatology, USZ, CH-8091 Zürich, Gloriastraßbe 25, Switzerland

\section{Received: 28 June 2005 Revised: 14 May 2008}

Accepted: 12 May 2010 Published: 12 May 2010

\section{References}

1. Gay S, Gay RE, Koopman WJ: Molecular and cellular mechanisms of joint destruction in rheumatoid arthritis: two cellular mechanisms explain joint destruction? Ann Rheum Dis 1993, 52(Suppl 1):S39-S47.

2. Muller-Ladner U, Gay RE, Gay S: Molecular biology of cartilage and bone destruction. Curr Opin Rheumatol 1998, 10:212-219.

3. Firestein GS: Invasive fibroblast-like synoviocytes in rheumatoid arthritis. Passive responders or transformed aggressors? Arthritis Rheum 1996, 39:1781-1790.

4. Pap T, Muller-Ladner U, Gay RE, Gay S: Fibroblast biology. Role of synovial fibroblasts in the pathogenesis of rheumatoid arthritis. Arthritis Res 2000, 2:361-367.

5. Muller-Ladner U, Kriegsmann J, Franklin BN, Matsumoto S, Geiler T, Gay RE, Gay S: Synovial fibroblasts of patients with rheumatoid arthritis attach to and invade normal human cartilage when engrafted into SCID mice. Am J Pathol 1996, 149:1607-1615.

6. Kullmann F, Judex M, Ballhorn W, Justen HP, Wessinghage D, Welsh J, Yen TJ, Lang B, Hittle JC, McClelland M, Gay S, Schölmerich J, Müller-Ladner U: Kinesin-like protein CENP-E is upregulated in rheumatoid synovial fibroblasts. Arthritis Res 1999, 1:71-80.

7. Aicher WK, Heer AH, Trabandt A, Bridges SL Jr, Schroeder HW Jr, Stransky G, Gay RE, Eibel H, Peter HH, Siebenlist U, et al:: Overexpression of zincfinger transcription factor Z-225/Egr-1 in synoviocytes from rheumatoid arthritis patients. J Immunol 1994, 152:5940-5948

8. Rutkauskaite E, Zacharias W, Schedel J, Muller-Ladner U, Mawrin C, Seemayer CA, Alexander D, Gay RE, Aicher WK, Michel BA, Gay S, Pap T: Ribozymes that inhibit the production of matrix metalloproteinase 1 reduce the invasiveness of rheumatoid arthritis synovial fibroblasts. Arthritis Rheum 2004, 50:1448-1456.

9. Seki T, Selby J, Haupl T, Winchester R: Use of differential subtraction method to identify genes that characterize the phenotype of cultured rheumatoid arthritis synoviocytes. Arthritis Rheum 1998, 41:1356-1364.

10. Neumann E, Judex M, Kullmann F, Grifka J, Robbins PD, Pap T, Gay RE, Evans CH, Gay S, Scholmerich J, Müller-Ladner U: Inhibition of cartilage destruction by double gene transfer of IL-1Ra and IL-10 involves the activin pathway. Gene Ther 2002, 9:1508-1519.

11. Neumann E, Kullmann F, Judex M, Justen HP, Wessinghage D, Gay S, Scholmerich J, Muller-Ladner U: Identification of differentially expressed genes in rheumatoid arthritis by a combination of complementary DNA array and RNA arbitrarily primed-polymerase chain reaction. Arthritis Rheum 2002, 46:52-63.

12. Gay S, Gay RE: Cellular basis and oncogene expression of rheumatoid joint destruction. Rheumatol Int 1989, 9:105-113.

13. Firestein GS, Echeverri F, Yeo M, Zvaifler NJ, Green DR: Somatic mutations in the p53 tumor suppressor gene in rheumatoid arthritis synovium. Proc Natl Acad Sci 1997, 94:10895-10900.

14. Kullmann F, Judex M, Neudecker I, Lechner S, Justen HP, Green DR, Wessinghage D, Firestein GS, Gay S, Scholmerich J, Müller-Ladner U: Analysis of the $\mathrm{p} 53$ tumor suppressor gene in rheumatoid arthritis synovial fibroblasts. Arthritis Rheum 1999, 42:1594-1600.

15. Muller-Ladner U, Kriegsmann J, Gay RE, Gay S: Oncogenes in rheumatoid arthritis. Rheum Dis Clin North Am 1995, 21:675-690.

16. Kraan MC, Haringman JJ, Weedon H, Barg EC, Smith MD, Ahern MJ, Smeets TJ, Breedveld FC, Tak PP: T cells, fibroblast-like synoviocytes, and granzyme B+ cytotoxic cells are associated with joint damage in patients with recent onset rheumatoid arthritis. Ann Rheum Dis 2004, 63:483-488
17. Tolboom TC, Huidekoper AL, Kramer IM, Pieterman E, Toes RE, Huizinga TW: Correlation between expression of CD44 splice variant v8-v9 and invasiveness of fibroblast-like synoviocytes in an in vitro system. Clin Exp Rheumatol 2004, 22:158-164.

18. Hashiramoto A, Sano H, Maekawa T, Kawahito Y, Kimura S, Kusaka Y, Wilder RL, Kato H, Kondo M, Nakajima H: C-myc antisense oligodeoxynucleotides can induce apoptosis and down-regulate Fas expression in rheumatoid synoviocytes. Arthritis Rheum 1999, 42:954-962.

19. Muller-Ladner U, Judex M, Justen HP, Wessinghage D, Welsh J, McClelland M, Gay S, Scholmerich J, Kullmann F: Analysis of gene expression patterns in rheumatoid synovial fibroblasts using RAP-PCR for differential display. Med Klin 1999, 94:228-232.

20. Mathieu-Daude F, Cheng R, Welsh J, McClelland M: Screening of differentially amplified cDNA products from RNA arbitrarily primed PCR fingerprints using single strand conformation polymorphism (SSCP) gels. Nucleic Acids Res 1996, 24:1504-1507.

21. Vogt TM, Welsh J, Stolz W, Kullmann F, Jung B, Landthaler M, McClelland M: RNA fingerprinting displays UVB-specific disruption of transcriptional control in human melanocytes. Cancer Res 1997, 57:3554-3561

22. Trenkle T, Welsh J, McClelland M: Differential display probes for CDNA arrays. Biotechniques 1999, 27:554-60. 562, 564

23. Masuda K, Masuda R, Neidhart M, Simmen BR, Michel BA, Muller-Ladner U, Gay RE, Gay S: Molecular profile of synovial fibroblasts in rheumatoid arthritis depends on the stage of proliferation. Arthritis Res 2002, 4:R8.

24. Schedel J, Seemayer CA, Pap T, Neidhart M, Kuchen S, Michel BA, Gay RE, Muller-Ladner U, Gay S, Zacharias W: Targeting cathepsin L (CL) by specific ribozymes decreases $\mathrm{CL}$ protein synthesis and cartilage destruction in rheumatoid arthritis. Gene Ther 2004, 11:1040-1047.

25. Fiehn C, Neumann E, Wunder A, Krienke S, Gay S, Muller-Ladner U: Methotrexate (MTX) and albumin coupled with MTX (MTX-HSA) suppress synovial fibroblast invasion and cartilage degradation in vivo. Ann Rheum Dis 2004, 63:884-886.

26. Muller-Ladner U, Elices MJ, Kriegsmann JB, Strahl D, Gay RE, Firestein GS, Gay S: Alternatively spliced CS-1 fibronectin isoform and its receptor VLA-4 in rheumatoid arthritis synovium. J Rheumatol 1997, 24:1873-1880

27. Arnett FC, Edworthy SM, Bloch DA, McShane DJ, Fries JF, Cooper NS, Healey LA, Kaplan SR, Liang MH, Luthra HS, et al: The American Rheumatism Association 1987 revised criteria for the classification of rheumatoid arthritis. Arthritis Rheum 1988, 31:315-324.

28. Neumann E, Lechner S, Tarner IH, Grifka J, Gay S, Ruschoff J, Renke B, Scholmerich J, Kullmann F, Muller-Ladner U: Evaluation of differentially expressed genes by a combination of CDNA array and RAP-PCR using the Atlaslmage 2.0 software. J Autoimmun 2003, 21:161-166.

29. Mangasser-Stephan K, Dooley S, Welter C, Mutschler W, Hanselmann RG: Identification of human semaphorin $\mathrm{E}$ gene expression in rheumatoid synovial cells by mRNA differential display. Biochem Biophys Res Commun 1997, 234:153-156.

30. Muller-Ladner U, Kriegsmann J, Tschopp J, Gay RE, Gay S: Demonstration of granzyme A and perforin messenger RNA in the synovium of patients with rheumatoid arthritis. Arthritis Rheum 1995, 38:477-484

31. Dimri GP, Campisi J: Altered profile of transcription factor-binding activities in senescent human fibroblasts. Exp Cell Res 1994, 212:132-140.

32. Pap T, Franz JK, Hummel KM, Jeisy E, Gay R, Gay S: Activation of synovial fibroblasts in rheumatoid arthritis: lack of expression of the tumour suppressor PTEN at sites of invasive growth and destruction. Arthritis Res 2000, 2:59-64.

33. Rinaldi N, Schwarz-Eywill M, Weis D, Leppelmann-Jansen P, Lukoschek M, Keilholz U, Barth TF: Increased expression of integrins on fibroblast-like synoviocytes from rheumatoid arthritis in vitro correlates with enhanced binding to extracellular matrix proteins. Ann Rheum Dis 1997, 56:45-51.

doi: $10.1186 / a r 3010$

Cite this article as: Neumann et al., Cell culture and passaging alters gene expression pattern and proliferation rate in rheumatoid arthritis synovial fibroblasts Arthritis Research \& Therapy 2010, 12:R83 